\title{
Serological Biomarker Panel in Diagnosis of Atrophic Gastritis and Helicobacter pylori Infection in Gastroscopy Referral Patients: Clinical Validation of the New-Generation GastroPane ${ }^{\circledR}$ Test
}

\author{
OLLI-PEKKA KOIVUROVA ${ }^{1}$, RITVA KOSKELA ${ }^{2}$, TIMO BLOMSTER ${ }^{2}$, ANTTI ALA-RÄMI ${ }^{2}$, \\ HENRI LUMME ${ }^{2}$, OLLI KETTUNEN ${ }^{2}$, JANNE HUKKANEN ${ }^{2}$, TUOMO J. KARTTUNEN ${ }^{3}$, \\ MARKUS MÄKINEN ${ }^{3,4}$, JUKKA RONKAINEN ${ }^{5,6}$ and KARI SYRJÄNEN ${ }^{7,8}$ \\ ${ }^{1}$ Departmernt of Endoscopy, Terveystalo Medical Center, Oulu, Finland; \\ ${ }^{2}$ Research Unit of Internal Medicine, Medical Research Center Oulu, \\ Oulu University Hospital, and University of Oulu, Oulu, Finland; \\ ${ }^{3}$ Cancer and Translational Medicine Research Unit, University of Oulu, Oulu, Finland; \\ ${ }^{4}$ Department of Pathology, Oulu University Hospital, Oulu, Finland; \\ ${ }^{5}$ Center for Life Course Health Research, University of Oulu, Oulu, Finland; \\ ${ }^{6}$ Primary Health Care Center, Tornio, Finland; \\ ${ }^{7}$ Molecular Oncology Research Center, Barretos Cancer Hospital, Barretos, Brazil; \\ ${ }^{8}$ SMW Consultants, Ltd., Kaarina, Finland
}

\begin{abstract}
Background/Aim: Prompted by the increasing demand of non-invasive diagnostic tools for screening of gastric cancer $(G C)$ risk conditions, i.e., atrophic gastritis (AG) and Helicobacter pylori (Hp) infection, the GastroPanel ${ }^{\circledR}$ test (GP: biomarker panel of PGI, PGII, G-17, Hp IgG ELISA) that was developed in the early 2000's, was recently updated to a new-generation (unified GP) test version. This clinical validation study evaluated the diagnostic accuracy of the newgeneration GP test in detection of $A G$ and $H p$ among gastroscopy referral patients in a University Clinic. Patients and Methods: Altogether, 522 patients were enrolled among the patients referred for gastroscopy at the Gastro Center, Oulu University Hospital (OUH). All patients underwent gastroscopy with biopsies classified using the Updated Sydney System (USS), and blood sampling for GP testing. Results: Biopsyconfirmed AG was found in 10.2\% (53/511) of the patients. The
\end{abstract}

This article is freely accessible online.

Correspondence to: Prof. Kari Syrjänen, MD, Ph.D., FIAC, SMW Consultants Ltd., Kylliäisentie 9, FI-21620 Kuusisto, Finland. Tel: +358405566810, e-mail: kasyrja@netti.fi

Key Words: Atrophic gastritis (AG), serological biomarker panel, new-generation GastroPanel, non-invasive test, clinical validation, gastroscopy, biopsies, updated Sydney System (USS), Helicobacter pylori, pepsinogen I, pepsinogen II, gastrin-17, Hp IgG antibody ELISA, diagnostic accuracy. overall agreement between the GP and the USS classification was $92.4 \%$ (95\%CI=90.0-94.6\%), with the weighted kappa $\left(k_{\mathrm{w}}\right)$ of 0.861 (95\% CI=0.834-0.883). In ROC analysis using moderate/severe $A G$ of the corpus $(A G C 2+)$ as the endpoint, $A U C=0.952 \quad(95 \% C I=0.891-1.000) \quad$ and $A U C=0.998$ (95\%CI=0.996-1.000) for PGI and PGI/PGII, respectively. Hp I $G$ antibody ELISA detected biopsy-confirmed Hp-infection with $A U C=0.993$ (95\%CI=0.987-0.999). Conclusion: The new generation GastroPanel ${ }^{\circledR}$ is a precise test for non-invasive diagnosis of atrophic gastritis and Hp-infection in dyspeptic patients referred for diagnostic gastroscopy.

It is estimated that of the $>1$ million annual cases of gastric cancer (GC), nearly $80 \%$ among males and $70 \%$ in women are due to lifestyle and environmental factors (1-5). Two risk factors exceed in importance all the others in pathogenesis of GC: i) Helicobacter pylori $(\mathrm{Hp})$ infection and ii) atrophic gastritis (AG) $(3,6,7)$. Hp itself is not a directly carcinogenic agent (8), but $\mathrm{Hp}$-induced $\mathrm{AG}$ is the single most severe risk condition of GC $(3,7,9)$. About $5-10 \%$ of all Hp-infected patients eventually develop moderate to severe AG, and the risk of GC increases in parallel with the severity of AG, reaching 90-fold in patients who have severe AG both in the corpus and in the antrum (so called pan-gastritis; AGP) $(3,6,7,10)$.

The intestinal type of GC develops in atrophic gastric mucosa as a stepwise process known as Correa cascade (3), through mild, moderate and severe AG, often accompanied by intestinal metaplasia (IM) and various degrees of dysplasia 
(7). This cascade may be interrupted by curative treatment of Hp-infection (3, 4, 9, 11-13). According to the Updated Sydney System classification (USS), AG is classified by its topographic location (antrum, corpus, or both) as AGA, AGC or AGP, respectively (14). AG and $\mathrm{Hp}$-infection can cause upper abdominal symptoms known as dyspepsia (15). It is still controversial, whether systematic Hp-eradication is effective in relieving dyspeptic symptoms $(9,10,15)$.

The Correa cascade takes decades to progress into GC, which makes possible to diagnose the precursor lesions given that a suitable screening test is available (16). AG has been traditionally diagnosed using gastroscopy and biopsies (3, 14, 17). However, this invasive method is expensive and felt uncomfortable by most patients, who prefer an inexpensive and non-invasive diagnostic test (18-20). Development of noninvasive methods were initiated in the 1980's by Miki et al. (21) and Samloff et al. (22) who introduced assays for pepsinogen (PG) measurement in blood samples. In the early 2000's, a biomarker panel was developed in Finland (Biohit Oyj, Helsinki), combining serum pepsinogen I (PGI) and II (PGII), gastrin-17 (G-17) and Hp antibody (Hp IgG), as an ELISA test known as GastroPanel ${ }^{\circledR}$ (GP) (23). The prime indications of this biomarker panel include the first-line diagnosis of dyspeptic patients (24-26), as well as screening of the risk conditions of GC (i.e., Hp and AG) $(27,28)$. This biomarker combination gives 1) accurate measurements of the capacity of corpus and antrum to produce gastric acid and G-17, respectively, 2) detects important gastric pathologies, like inflammation, as well as 3) estimates the grade and topography of AG (20-22, 28-31).

Since its introduction, the GP test has been extensively tested in different clinical and screening settings worldwide (32-40). The GP literature accumulated until 2016/2017 was covered by two separate meta-analyses $(31,41)$, disclosing pooled sensitivity of $72-75 \%$ and pooled specificity close to 95\% for the AGC endpoint. Since the appearance of these two meta-analyses, the number of relevant studies and tested patients have almost doubled (42-47, only few to cite), indicating an increased global interest in this test (23, 25-29). Before finalizing the GastroPanel ${ }^{\circledR}$ quick (POC) test, a newgeneration (unified) GastroPanel ${ }^{\circledR}$ test was introduced, harmonizing the ELISA processing conditions of the 4 biomarkers. This new test version was recently validated in patients at high risk for AG (48) and in those with high Hpprevalence (49).

Unfortunately, the first study was subject to verification bias, i.e., only GP-test positive patients were examined by gastroscopy and biopsies (48), whereas the latter was compromised by an insufficient number of AG patients (49). With a $100 \%$ biopsy-confirmed design, the present study on gastroscopy referral patients provides unbiased estimates on the diagnostic accuracy of the GP test for both AG and Hp endpoints, and concludes the series of clinical validation studies of the unified GP test.
Table I. Demographics and clinical information required for the GastroPanel® test.

\begin{tabular}{lcc}
\hline Characteristics & $\begin{array}{c}\text { Number of } \\
\text { patients } \\
\mathrm{n}=522\end{array}$ & $\begin{array}{c}\text { Percent } \\
\text { of total } \\
100 \%\end{array}$ \\
\hline Gender & & \\
Women & 348 & 66.7 \\
Men & 174 & 33.3 \\
Age (Median; Range) & 55.8 years & $(18-86$ years) \\
History recorded in GastroPanel ${ }^{\circledR}$ & & \\
(GP) referral form & & \\
1. Helicobacter eradication & & \\
Not eradicated & 405 & 77.6 \\
Yes, less than a year ago & 14 & 2.7 \\
Yes, over a year ago & 68 & 13.0 \\
Responder does not know & 35 & 6.7 \\
2. Use of PPI-medication & & \\
No PPI-medication & 184 & 35.2 \\
Continuous use of PPI-medication & 219 & 42.0 \\
Occasional use of PPI-medication & 112 & 21.5 \\
Responder does not know & 7 & 1.3 \\
3. Break in PPI-medication prior to & & \\
GP test (n=320) (Median; Range) & 7 days & $(1-60$ days) \\
4. Symptoms of high acidity (heartburn) & & \\
No symptoms of high acidity & 343 & 65.7 \\
Continuous symptoms of high acidity & 173 & 33.1 \\
Data missing & 6 & 1.1 \\
5. Use of NSAID-medication & & \\
No use of NSAID-medication & 410 & 78.5 \\
Continuous use of NSAID-medication & 108 & 20.7 \\
Data missing & 4 & 0.8 \\
\hline
\end{tabular}

\section{Patients and Methods}

The patients were enrolled at the outpatient Department of Gastroenterology, Oulu University Hospital (OUH) Gastro Center, among the consecutive patients referred for gastroscopy with a wide variety of abdominal symptoms. The potentially eligible patients (18 years or older) were identified among the gastroscopy referral outpatients, and were asked to sign a written consent. All consented patients were interviewed using previously validated questionnaires (50). The exclusion criteria were the same as listed in the previous study (48). The study protocol followed the Declaration of Helsinki, and was approved by the Ethics Committee of the Northern Ostrobothnia Hospital District (DNo 060/2015). A cohort of 522 patients completed the study protocol. The key characteristics of the patients and their symptoms are summarized in Table I. Of the 522 patients, $66.7 \%(n=348)$ were women and $33.3 \%$ were men. The median age of the patients was 58 years (range 18-86 years).

Questionnaire of the symptoms. GI-symptom questionnaire was completed prior to blood sampling (50). The results of the questionnaire (Table I) will be the subject of a separate analysis.

Preparation for GastroPanel ${ }^{\circledR}$ sampling. Proper performance of GastroPanel ${ }^{\circledR}$ test requires that some preparatory measures are being 
Table II. Biomarker levels stratified by the GastroPanel ${ }^{\circledR}$ diagnostic categories.

\begin{tabular}{lccccccc}
\hline GP diagnosis & $\begin{array}{c}\text { No. of } \\
\text { cases }\end{array}$ & $\begin{array}{c}\text { PGI } \\
(\mathrm{M} \pm \mathrm{SD})\end{array}$ & $\begin{array}{c}\text { PGII } \\
(\mathrm{M} \pm \mathrm{SD})\end{array}$ & $\begin{array}{c}\text { PGI/PGII } \\
(\mathrm{M} \pm \mathrm{SD})\end{array}$ & $\begin{array}{c}\mathrm{G}-17 \mathrm{~b} \\
(\mathrm{M} \pm \mathrm{SD})\end{array}$ & $\begin{array}{c}\mathrm{G}-17 \mathrm{~s} \\
(\mathrm{M} \pm \mathrm{SD})\end{array}$ & $\begin{array}{c}\mathrm{HpAb} \\
(\mathrm{M} \pm \mathrm{SD})\end{array}$ \\
\hline Normal & 446 & $100.6(53.2)$ & $11.7(6.4)$ & $8.8(2.3)$ & $2.6(4.2)$ & $8.8(9.6)$ & $13.9(2.5)$ \\
Hp-gastritis & 35 & $123.8(58.6)$ & $27.3(16.4)$ & $5.3(1.9)$ & $7.8(7.3)$ & $18.8(13.9)$ & $684.7(571.6)$ \\
AGA & 10 & $96.1(45.5)$ & $14.1(7.9)$ & $7.7(2.9)$ & $0.6(0.3)$ & $1.5(0.7)$ & $173.1(209.9)$ \\
AGC & 27 & $11.4(10.2)$ & $10.4(4.1)$ & $1.0(0.8)$ & $25.3(11.6)$ & $35.0(17.3)$ & $79.2(187.5)$ \\
AGP & 1 & 11.4 & 5.4 & 2.1 & 0.4 & 0.6 & 14.9 \\
\hline Total series & 519 & & & & &
\end{tabular}

AGA, Atrophic antrum gastritis; AGC, atrophic corpus gastritis; AGP, atrophic pan-gastritis.

strictly followed, including discontinuation of PPI medication one week before testing, as described before (48). If this was not possible, a notice of PPI use and its eventual discontinuation should be included in the GP request form $(23,29,30)$.

Sample processing for GastroPanel ${ }^{\circledR}$ test. GP test results are interpreted by the GastroSoft ${ }^{\circledR}$ application (Biohit Oyj, Helsinki), necessitating completion of the GP request form with pertinent clinical information $(23,29,48,49)$ (Table I). A minimum of $2 \mathrm{ml}$ EDTA plasma from a fasting blood sample was taken into an EDTA tube, frozen instantly $\left(-70^{\circ} \mathrm{C}\right)$, as instructed by the manufacturer $(23,29,48,49)$.

Stimulated G-17 (G-17s). In addition to the fasting G-17 sample (G$17 \mathrm{~b})$, another blood sample was collected to measure the stimulated G-17 (G-17s) $(26,28,30,31)$, collected 20 min after intake of a special protein drink (Biohit Oyj).

GastroPanel ${ }^{\circledR}$ testing. All plasma samples were delivered to Biohit Oyj (Helsinki) for analysis with the new generation GP test following the instructions detailed elsewhere $(23,29,48)$.

GastroPane $l^{\circledR}$ results are interpreted by GastroSoft ${ }^{\circledR}$ application. GastroPanel ${ }^{\circledR}$ test is designed for use with the Updated Sydney System (USS) classification of gastritis $(14,17)$, both using the same diagnostic categories: a) normal mucosa, b) $\mathrm{Hp}$-gastritis with no atrophy, c) atrophic gastritis of the antrum (AGA), d) atrophic gastritis of the corpus (AGC), and e) atrophic gastritis in both antrum and corpus (AGP) $(23,26,28,29,48,49)$.

Gastroscopy and biopsies. Gastroscopy biopsies followed the protocol of the USS, targeting to both the antrum and corpus (14, 17). Macroscopic endoscopy findings were classified using the adopted practice of the clinic (48), the endoscopist being blinded to the GP results. All biopsies were examined by expert pathologists at the Department of Pathology, OUH, and the diagnoses were classified using the USS classification $(14,17)$ and grading of the AGA, AGC and AGP as reported before (48).

Statistical analysis. The descriptive statistics was done using the conventional tests. Sensitivity (SE), specificity (SP), positive predictive value (PPV), negative predictive value (NPV) and their 95\% CI, of the GP test biomarkers were calculated using the algorithm of Seed et al. (2001) (51). ROC (Receiver Operating
Characteristics) analysis was used to identify the optimal SE/SP balance for both endpoints (AGA and AGC), and AUC values were compared by the roccomb test $(48,49)$. The agreement between the different tests was calculated separately using overall agreement $(\mathrm{OA})$ and intra-class correlation coefficient (ICC) test for weighted kappa $\left(\mathrm{K}_{\mathrm{w}}\right)$. In addition, Fagan's nomogram (52) was constructed to give the post-test predictions for AGC at a population level, based on the indicators calculated for the $\mathrm{AGC} 2+$ endpoint: i) the pre-test probability; ii) positive likelihood ratio $(\mathrm{LR}+)$, and iii) negative likelihood ratio. All statistical analyses were performed using the SPSS 27.0.1.0 for Windows (IBM, NY, USA) and STATA/SE 17.0 software (STATA Corp., TX, USA). All tests were deemed significant at the level of $p<0.05$.

\section{Results}

Table I summarises the age and gender of patients and their medical history requested in the GastroPanel ${ }^{\circledR}$ referral form. The symptoms recorded by the GI-questionnaire are not reported in this communication. The majority $(66.7 \%)$ of patients were women. The mean age of patients was 55.7 years ( $\mathrm{SD}=15.4$ years). Of the specific items necessary for the GastroPanel ${ }^{\circledR}$ test, the frequency of prior Hp-eradication was $15.7 \%$, continuous use of PPI medication was reported by $42 \%$ of patients, symptoms of high acidity by $33.1 \%$ (continuously) as well as continuous use of NSAIDs by $20.7 \%$ of the study subjects. The correlation of GI symptoms with GastroPanel ${ }^{\circledR}$ results are to be reported in a subsequent paper. The biomarker values $(\mathrm{M} \pm \mathrm{SD})$ in the five diagnostic categories of the GastroPanel ${ }^{\circledR}$ test are summarized in Table II, with no unexpected findings. Table III gives the biomarker levels across the diagnostic categories of the USS classification. As compared to the GP test categories, the most visible differences are seen in $\mathrm{Hp}$-antibody titres.

AGA was diagnosed in 16 patients, AGC in 23 cases and AGP in 13 patients in the biopsies (Table IV). The unadjusted overall agreement (OA) between the GastroPanel ${ }^{\circledR}$ test and the USS classification is 0.914 (i.e., $91.4 \%$ ). When adjusted for the correctly diagnosed AGC component of the AGP by the GP test in 5/13 cases, the adjusted OA increases to $92.4 \%$ 
Table III. Biomarker levels across the five categories the USS classification.

\begin{tabular}{lccccccc}
\hline USS grade & $\begin{array}{c}\text { No of } \\
\text { cases }\end{array}$ & $\begin{array}{c}\text { PGI } \\
(\mathrm{M} \pm \mathrm{SD})\end{array}$ & $\begin{array}{c}\text { PGII } \\
(\mathrm{M} \pm \mathrm{SD})\end{array}$ & $\begin{array}{c}\text { PGI/PGII } \\
(\mathrm{M} \pm \mathrm{SD})\end{array}$ & $\begin{array}{c}\mathrm{G}-17 \mathrm{~b} \\
(\mathrm{M} \pm \mathrm{SD})\end{array}$ & $\begin{array}{c}\mathrm{G}-17 \mathrm{~s} \\
(\mathrm{M} \pm \mathrm{SD})\end{array}$ & $\begin{array}{c}\mathrm{HpAb} \\
(\mathrm{M} \pm \mathrm{SD})\end{array}$ \\
\hline Normal & 435 & $99.4(53.2)$ & $11.8(7.0)$ & $8.8(2.3)$ & $2.6(4.5)$ & $8.7(9.8)$ & $15.0(10.4)$ \\
Hp-gastritis & 23 & $123.3(56.8)$ & $23.2(13.8)$ & $5.9(2.0)$ & $5.5(5.9)$ & $13.6(11.1)$ & $632.7(490.8)$ \\
AGA & 16 & $130.6(64.4)$ & $22.3(19.2)$ & $7.5(3.6)$ & $6.5(7.8)$ & $17.2(18.1)$ & $344.5(556.9)$ \\
AGC & 23 & $17.5(28.9)$ & $11.4(8.1)$ & $1.3(1.6)$ & $25.7(11.5)$ & $33.9(19.9)$ & $92.7(224.0)$ \\
AGP & 13 & $69.0(56.7)$ & $19.0(11.9)$ & $3.9(3.3)$ & $9.0(9.8)$ & $17.2(11.9)$ & $401.2(631.3)$ \\
\hline
\end{tabular}

Total series 510

USS, Updated Sydney system; AGA, atrophic antrum gastritis; AGC, atrophic corpus gastritis; AGP, atrophic pan-gastritis.

$(95 \% \mathrm{CI}=90.0-94.6 \%)$. The weighted kappa test $\left(\mathrm{K}_{\mathrm{W}}\right)$ for the two-test agreement is: non-adjusted $\mathrm{K}_{\mathrm{W}}=0.850$ and adjusted $\mathrm{K}_{\mathrm{W}}=0.861(95 \% \mathrm{CI}=0.834-0.883)$.

Regarding the agreement in diagnosis of AG by GastroPanel ${ }^{\circledR}$ test and macroscopic gastroscopy findings (Table V), 480/520 cases were similarly diagnosed by both tests: $\mathrm{OA}=92.0 \% \quad(95 \% \mathrm{CI}=90.0-94.5 \%)$. After an $\mathrm{AG}$ diagnosis in the GP test, OR for detecting AG on gastroscopy is $23.23(95 \% \mathrm{CI}=10.78-50.03)(p=0.0001)$.

Table VI shows the reproducibility between gastroscopy and the USS classification in diagnosis of AG. Altogether, $467 / 512$ cases are similarly diagnosed (AG+/AG-) by the two tests, with $\mathrm{OA}=91.2 \%$. The $\mathrm{OR}$ for diagnosing $\mathrm{AG}$ in the biopsies after AG diagnosed in gastroscopy is 23.21, with 95\%CI ranging between 11.24-47.92 ( $p=0.0001)$.

Table VII depicts the precision of the GastroSoft ${ }^{\circledR}$ AGAand AGC-profiles as predictors of AGA and AGC in the biopsies. For AGA, sensitivity and PPV of GastroSoft ${ }^{\circledR}$ AGA profile are poor but specificity and NPV are high, with AUC values ranging between 0.507 and 0.526 . The AGC-profile predicts the biopsy-confirmed AGC2+ with $92.0 \% \mathrm{SE}$ and $99 \%$ $\mathrm{SP}$, with $\mathrm{AUC}=0.955(95 \% \mathrm{CI}=0.900-1.000)$. For any grade of AGC, AUC reaches the value of 0.859 (95\%CI=0.785-0.933).

Table VIII summarises the diagnostic accuracy of GastroPanel ${ }^{\circledR}$ biomarkers (PGI, PGI/PGII) and G-17s in diagnosis of AGC and AGA, respectively. As expected, G-17s is of limited value in diagnosing AGA, whereas PGI and PGI/PGII ratio are highly accurate in diagnosis of AGC. Using the AGC2+ (moderate/severe AGC) as the endpoint, both PGI $(30 \mu \mathrm{g} / \mathrm{l})$ and PGI/PGII ratio (3.0) are almost $100 \%$ accurate diagnostic tests, with sensitivity of $92.0 \%$ and $100 \%$, and specificity of $98.8 \%$ and $98.6 \%$, respectively. Figure 1 shows the ROC curve for PGI using the AGC2+ endpoint, with the $\mathrm{AUC}=0.952$ (95\% CI=0.891-1.000). The ROC curve is even more impressive for PGI/PGII ratio, with the AUC=0.998 (95\%CI=0.996-1.000) (Figure 2). Hp IgG ELISA of the GastroPanel ${ }^{\circledR}$ detects biopsyconfirmed Hp-infection (any topography) with AUC $=0.992$ $(95 \% \mathrm{CI}=0.987-0.999)$, as shown in Figure 3.
The Fagan's nomogram (52) illustrated in Figure 4 was drawn by entering the diagnostic indicators of PGI for the AGC2+ endpoint (Table VIII), produced by STATA (diagti algorithm): i) the pre-test probability 0.049 ; ii) $\mathrm{LR}+74.4$, and iii) LR- 0.081. As the post-test predictions of AGC in a population, Fagan's nomogram implicates that an AGC diagnosis in the GP test predicts AGC2+ with the likelihood of $80 \%$, whereas the likelihood is close to $0 \%(0.4 \%)$ if the GP test result is negative for AGC.

\section{Discussion}

Before entering into the GastroPanel ${ }^{\circledR}$ validation data, a few remarks need to be made. First: The GP test biomarkers measure the function and structure of both the antrum $(\mathrm{G}-$ $17 \mathrm{~b}, \mathrm{G}-17 \mathrm{~s}$ ) and the corpus (PGI, PGII, PGI/PGII ratio) separately $(28-31,53)$. The GP biomarker profiles reflect this topographic location of $\mathrm{AG}$ in the antrum (AGA) and corpus (AGC), and these two conditions should be kept separately while validating the diagnostic accuracy of the GP test (26, 28-31, 53). Second: Mild AGA and AGC are poorly reproducible histopathological diagnoses (14, 17, 26, 30-32, $34,40,41,53)$, and should never be used as the endpoint while calculating the diagnostic accuracy of PGI (PGI/PGII) and $\mathrm{G}-17$, respectively. Instead, only moderate/severe AG (AGC2+, AGA2+) should be used in these calculations (26, $28,31,41,54)$. Third: Low G-17b values are due to high acid output of the corpus in the vast majority of cases, while AGA is a far more uncommon cause of low G-17b $(23,26-$ $29,31,41,53)$. Because of this dual regulation, G-17b cannot be an accurate biomarker of AGA only $(30,31,41)$. In this respect, protein-stimulated $\mathrm{G}-17(\mathrm{G}-17 \mathrm{~s})$ is more helpful, but even then, truly low levels of G-17 are encountered only in moderate/severe AGA (AGA2+) when G-cells are absent $(30,53)$. Due to these inherent physiological principles, the accuracy of the GP test in diagnosis of AGA never reaches the level obtained in diagnosis of AGC $(26,31,41,48,49)$. 
Table IV. Agreement between GastroPanel ${ }^{\circledR}$ test and the USS classification.

\begin{tabular}{|c|c|c|c|c|c|c|}
\hline \multirow[t]{2}{*}{ GastroPanel } & \multicolumn{5}{|c|}{ The Updated Sydney System (USS) } & \multirow[t]{2}{*}{ Total } \\
\hline & Normal & Hp-gastritis & AGA & AGC & AGP & \\
\hline Normal & 427 & 2 & 6 & 1 & 3 & 439 \\
\hline Hp-gastritis & 0 & 19 & 9 & 1 & 5 & 34 \\
\hline AGA & 7 & 2 & 1 & 0 & 0 & 10 \\
\hline AGC & 2 & 0 & 0 & 20 & 5 & 27 \\
\hline \multirow[t]{2}{*}{ AGP } & 0 & 0 & 0 & 1 & 0 & 1 \\
\hline & \multicolumn{5}{|c|}{$\begin{array}{l}\text { Overall agreement (OA): 467/511;0.914 }(95 \% \mathrm{CI}=0.889-0.938) \text {; } \\
\text { *Adjusted OA: } 472 / 511 ; 0.924(95 \% \mathrm{CI}=0.900-0.946)\end{array}$} & 511 \\
\hline
\end{tabular}

**Weighted kappa (Kw): ICC $=0.850$ (95\% CI=0.821-0.874); *Adjusted Kw: ICC=0.861 (95\%CI=0.834-0.883). *Adjusted for the correctly diagnosed AGC among AGP cases; **Weighted kappa (ICC; parallel model, two-way random, consistency); AGA, Atrophic antrum gastritis; AGC, atrophic corpus gastritis; AGP, atrophic pan-gastritis.

Table V. Agreement between GastroPanel ${ }^{\circledR}$ and gastroscopy in diagnosis of atrophic gastritis $(A G)$.

\begin{tabular}{|c|c|c|c|}
\hline \multirow[t]{2}{*}{ GastroPanel ${ }^{\circledR}$} & \multicolumn{2}{|c|}{ Gastroscopy } & \multirow[t]{2}{*}{ Total no. of cases } \\
\hline & *Atrophy & No atrophy & \\
\hline AG (AGA or AGC) & 20 & 18 & 38 \\
\hline \multirow[t]{2}{*}{ No $\mathrm{AG}^{* *}$} & 22 & 460 & 488 \\
\hline & \multicolumn{2}{|c|}{$\begin{array}{l}\text { Overall agreement }(\mathrm{OA}): 480 / 520 ; 0.920(95 \% \mathrm{CI}=0.900-0.945) \\
\text { Regular (Cohen's kappa) k=0.458 }(95 \% \mathrm{CI}=0.388-0.524) \\
\text { Odds Ratio }(\mathrm{OR})=23.23(95 \% \mathrm{CI}=10.78-50.03)(p=0.0001)\end{array}$} & 520 \\
\hline
\end{tabular}

*Clinically definite or strongly suggestive; **includes categories normal and Hp-gastritis; AG, Atrophic gastritis; AGA, atrophic antrum gastritis; AGC, atrophic corpus gastritis.

Table VI. Agreement between gastroscopy and the USS classification in diagnosis of AG.

\begin{tabular}{|c|c|c|c|}
\hline \multirow[t]{2}{*}{ Gastroscopy } & \multicolumn{2}{|c|}{ The updated Sydney system } & \multirow[t]{2}{*}{ Total no. of cases } \\
\hline & $* *$ Atrophy & No atrophy & \\
\hline *Atrophy & 25 & 17 & 42 \\
\hline \multirow[t]{2}{*}{ No atrophy } & 28 & 442 & 470 \\
\hline & \multicolumn{2}{|c|}{$\begin{array}{l}\text { Overall agreement }(\mathrm{OA}): 467 / 512 ; 0.912(95 \% \mathrm{CI}=0.887-0.936) \\
\text { Regular (Cohen's kappa) k=0.480 }(95 \% \mathrm{CI}=0.410-0.544) \\
\text { Odds Ratio }(\mathrm{OR})=23.21(95 \% \mathrm{CI}=11.24-47.92)(p=0.0001)\end{array}$} & 512 \\
\hline
\end{tabular}

*Clinically definite or strongly suggestive; **includes AG of any type (AGA, AGC, AGP); AGA, Atrophic antrum gastritis; AGC, atrophic corpus gastritis; AGP, atrophic pan-gastritis.

According to a comprehensive review, testing computer models that included symptoms, clinical history, risk factors, and patient demographics, clinical symptoms are of limited value in making a distinction between organic and functional dyspepsia (15). The original idea of the GastroPanel ${ }^{\circledR}$ designers was to develop a non-invasive alternative to invasive gastroscopy for the routine diagnosis of dyspepsia $(23,26,28,29)$. To fulfil this intent, the diagnostic agreement between the GP test and gastroscopic examination is of vital importance. In the present cohort, the agreement 
Table VII. Performance indicators of GastroSoft ${ }^{\circledR}$ report (AGA, AGC) in the diagnosis of biopsy-confirmed AGA and AGC.

\begin{tabular}{lccccc}
\hline Endpoint & Sensitivity & Specificity & PPV & NPV & AUC \\
\hline *AGA & $3.4(0.1-17.8)$ & $97.9(96.2-99.0)$ & $9.1(0.2-41.3)$ & $94.4(92.0-96.3)$ & $0.507(0.472-0.541)$ \\
AGA2+ & $7.1(0.2-33.9)$ & $98.0(96.3-99.0)$ & $9.1(0.2-41.3)$ & $97.4(95.6-98.6)$ & $0.526(0.455-0.596)$ \\
**AGC & $72.2(54.8-85.8)$ & $99.6(98.5-99.9)$ & $92.9(76.5-99.1)$ & $97.9(96.2-99.0)$ & $0.859(0.785-0.933)$ \\
AGC2+ & $92.0(74.0-99.0)$ & $99.0(97.6-99.7)$ & $82.1(63.1-93.9)$ & $99.6(98.5-99.9)$ & $0.955(0.900-1.000)$ \\
\hline
\end{tabular}

*AGA of any grade; AGA2+ (moderate/severe AGA); **AGC of any grade; AGC2+ (moderate/severe AGC); AGA, Atrophic antrum gastritis; AGC, atrophic corpus gastritis; AGP, atrophic pan-gastritis.

Table VIII. Performance indicators of G-17s (3.0 pmol/l cut-off), PGI (15 and $30 \mu \mathrm{g} / \mathrm{l}$ cut-off) and PGI/PGII (3.0 cut-off) in diagnosis of biopsyconfirmed $A G A$ and $A G C$.

\begin{tabular}{|c|c|c|c|c|c|}
\hline Endpoint & Sensitivity & Specificity & PPV & NPV & AUC \\
\hline \multicolumn{6}{|l|}{ G-17s: } \\
\hline$* A G A$ & $10.7(2.3-28.2)$ & $69.5(65.0-73.8)$ & $2.2(0.5-6.3)$ & $92.4(89.1-95.1)$ & $0.402(0.339-0.464)$ \\
\hline $\begin{array}{l}\text { AGA2+ } \\
\text { PGI (15): }\end{array}$ & $15.4(1.9-45.4)$ & $70.4(66.0-74.6)$ & $1.4(0.2-5.1)$ & $96.7(94.2-98.3)$ & $0.429(0.325-0.533)$ \\
\hline$* *$ AGC & $55.6(38.1-72.1)$ & $99.8(98.8-100.0)$ & $95.2(76.2-99.9)$ & $96.7(94.7-98.1)$ & $0.777(0.694-0.859)$ \\
\hline $\begin{array}{l}\mathrm{AGC} 2+ \\
\text { PGI (30): }\end{array}$ & $76.0(54.9-90.6)$ & $99.6(98.5-100.0)$ & $90.5(69.6-98.8)$ & $98.8(97.3-99.5)$ & $0.878(0.792-0.963)$ \\
\hline$* * A G C$ & $72.2(54.8-85.8)$ & $99.4(98.2-99.9)$ & $89.7(72.6-97.8)$ & $97.9(96.2-99.0)$ & $0.858(0.784-0.932)$ \\
\hline $\begin{array}{l}\text { AGC2+ } \\
\text { PGI/PGII: }\end{array}$ & $92.0(74.0-99.0)$ & $98.8(97.3-99.5)$ & $79.3(60.3-92.0)$ & $99.6(98.5-99.9)$ & $0.954(0.899-1.000)$ \\
\hline$* *$ AGC & $77.8(60.8-89.9)$ & $99.2(97.8-99.8)$ & $87.5(71.0-96.5)$ & $98.3(96.7-99.3)$ & $0.885(0.816-0.954)$ \\
\hline $\mathrm{AGC} 2+$ & $100(86.3-100)$ & $98.6(97.0-99.4)$ & $78.1(60.0-90.7)$ & $100(99.2-100)$ & $0.993(0.987-0.998)$ \\
\hline
\end{tabular}

*AGA of any grade; AGA2+ (moderate/severe AGA); **AGC of any grade; AGC2+ (moderate/severe AGC); AGA, Atrophic antrum gastritis; AGC, atrophic corpus gastritis; AGP, atrophic pan-gastritis.

between these two methods is excellent (92\%); 480/520 cases are concordantly diagnosed as AG, and the likelihood for disclosing AG on gastroscopy among the patients whose GP tests indicate AG has $\mathrm{OR}=23.2$ (Table V). This close concordance between the two techniques provides strong support to the practice that all patients with the AG profile in the GP test should be referred for gastroscopy $(23,26,28$ 31, 48, 49, 53). Noteworthy, in experienced hands, gastroscopic diagnosis of AG also closely (91.2\%) concurs with the AG diagnosis in the biopsies (Table VI). Because of the equal (91.2-92\%) concordance of i) the GP test and ii) gastroscopy with the biopsy histology, this leaves space for weighting between a non-invasive and an invasive test option in the primary diagnosis of dyspeptic symptoms.

Regarding classification of gastritis, the most widely used systems include the Updated Sydney System (USS) $(14,17)$ and OLGA/OLGIM staging (55). The GP test has been optimised for use with the USS, both including 5 diagnostic categories $(14,17,23,28-31,41,48,49,53)$, which makes it straighforward to calculate the reproducibility of the two tests by applying the weighted kappa $\left(\mathrm{K}_{\mathrm{W}}\right)$ test. When this was done (Table IV), the agreement calculated using the $\mathrm{K}_{\mathrm{w}}$ test is 0.850 and 0.861 , as non-adjusted and adjusted, respectively. The corresponding figures for overall agreement (OA) between the GP test and the USS classification are $91.4 \%$ and $92.4 \%$, respectively. Both these values are classified as "almost perfect" (0.8-1.0), while categorizing the tests that measure reproducibility. This lends further support to the statement that the GP test bears a close concordance with the USS classification (23, 28-31, 41, 48, $49,53)$. In this context, a word of caution must be stated against the use of OLGA staging (55) in validation of GP test, because this is not feasible. OLGA staging combines varying grades of AGA and AGC into one and the same OLGA stage (55). This results in unpredictable values of the antrum- and corpus-specific GP biomarkers across the OLGA stages, which obscures an accurate linking of specified GP biomarker profiles to individual OLGA stages $(30,31,41,53)$.

GastroSoft ${ }^{\circledR}$ defines biomarker profiles distinct for AGA (low G-17b and G-17s, Hp+) and AGC (low PGI, PGI/PGII ratio, high G-17b) $(23,26,28-31,48,49,53)$, that were tested for their diagnostic accuracy for biopsy-confirmed AGA and AGC (Table VII). Not unexpectedly, the sensitivity of the 


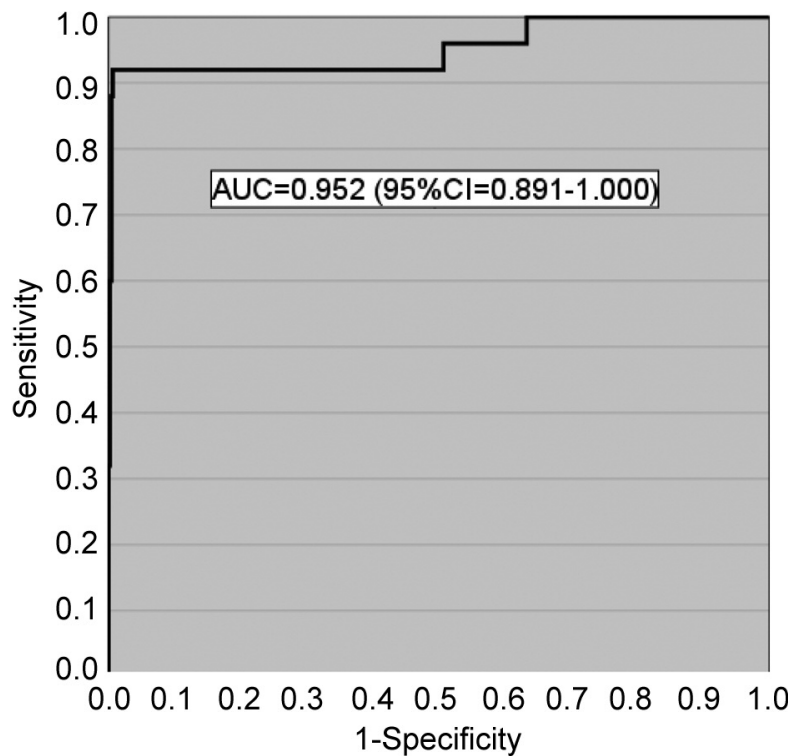

Figure 1. Pepsinogen I biomarker in detecting biopsy-confirmed moderate/severe atrophic corpus gastritis $(A G C)$ in receiver operating characteristics (ROC) analysis.

AGA profile in diagnosis of AGA $(n=10)$ in the biopsies is low $(3.4-7.0 \%)$, whereas specificity is high $(98 \%)$, resulting in $\mathrm{AUC}=0.526$. This low sensitivity of the GP test for AGA is explained by the dual role of G-17 as a marker of i) AGA, and ii) high acid output. As the cause of low G-17, the latter is far more common than the former, e.g., in this cohort $n=16$ (Table IV) and $n=173$ (Table I), respectively. Because of this dual mode of regulation, G-17b can never be a highly sensitive biomarker of AGA $(23,26-29,31,41,53)$. This is in sharp contract to AGC, while the AGC-profile of GastroSoft ${ }^{\circledR}$ detects the biopsy-confirmed AGC2+ with 92.0 SE and 99.0\% $\mathrm{SP}$, equivalent to $\mathrm{AUC}=0.955$.

When different cut-off values are used instead of the GastroSoft ${ }^{\circledR}$ profiles, the diagnostic accuracy remains unchanged (Table VIII). For PGI, $30 \mu \mathrm{g} / \mathrm{l}$ seems to be the optimal cut-off, being also used in the majority of the published studies $(23,29,30,31,41)$. For the AGC2+ endpoint, the highest diagnostic accuracy is obtained with the PGI/PGII ratio (3.0 cut-off). These outstanding AUC values are confirmed by the ROC analysis (Figure 1 and Figure 2), with $\mathrm{AUC}=0.952$ and $\mathrm{AUC}=0.998$ for $\mathrm{PGI}$ and PGI/PGII, respectively. These AUC values are superior to the HSROC (hierarchical summary ROC) calculated by Zagari et al. (2017) in their recent meta-analysis, with the pooled SE of $74.7 \%$ and pooled SP of $95.6 \%$ for PGI in diagnosis of $\mathrm{AGC}$ (i.e., $\mathrm{AUC}=0.851$ ) (41).

Another important role of the GP test is in diagnosis of Hp infections $(23,29,31)$. During the past several years,

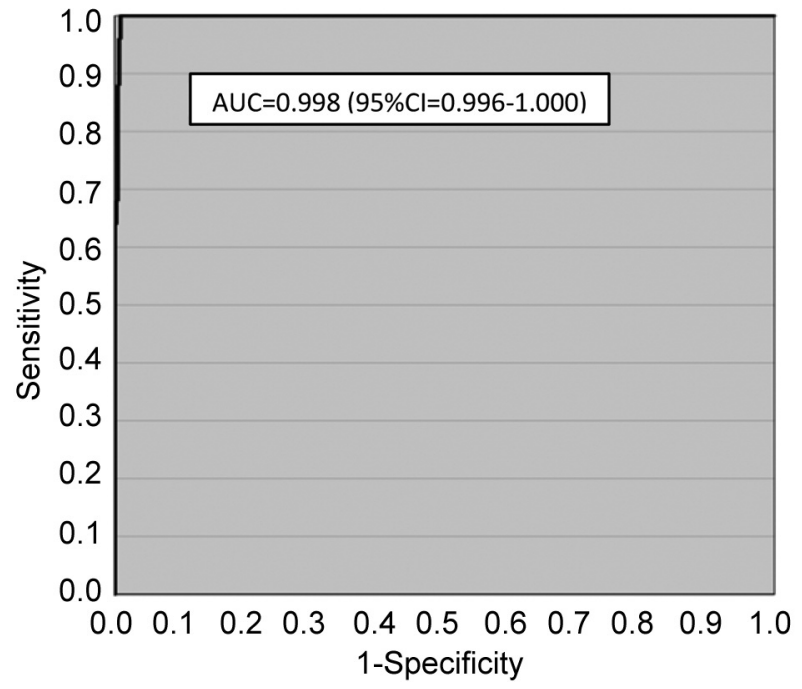

Figure 2. Pepsinogen I/Pepsinogen II ratio in detecting biopsyconfirmed moderate/severe atrophic corpus gastritis (AGC) in receiver operating characteristics (ROC) analysis.

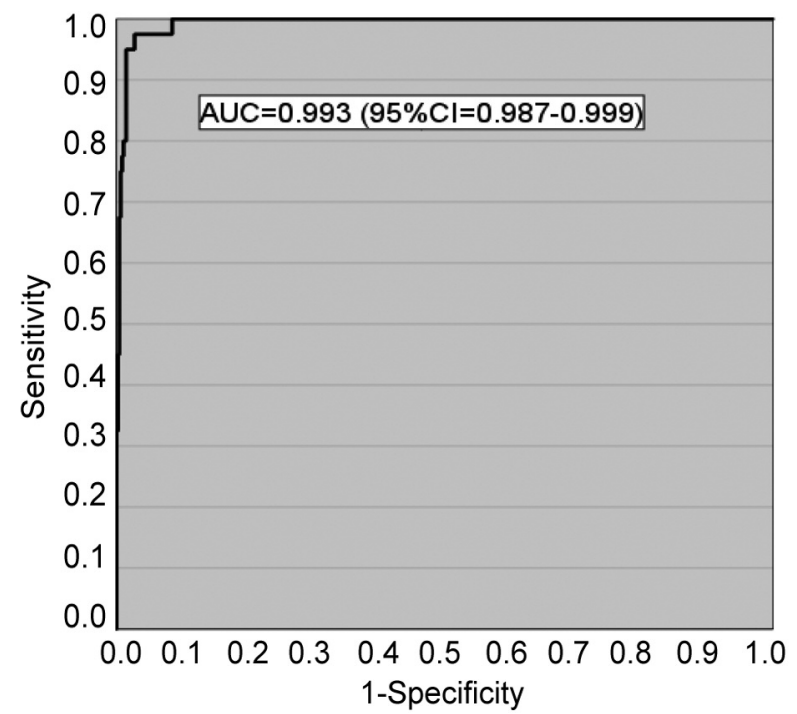

Figure 3. Helicobacter pylori IgG ELISA (enzyme-linked immunosorbent assay) in detecting biopsy-confirmed Helicobacter pylori (antrum/corpus) in receiver operating characteristics (ROC) analysis.

comprehensive reviews have been published on the limitations of the conventional Hp-tests in different clinical conditions $(10,56-59)$, and their shortcomings have been listed in all European Consensus Reports since 1996 (10, 58, 59). This includes both of the most widely used Hp-tests: the 13C-Urea Breath Test (UBT) and Stool Antigen test (SAT) (60). The accumulated evidence leaves little doubt that 
several clinical conditions seriously impede the diagnostic accuracy of the UBT and SAT tests, false-negative and falsepositive results being recorded in up to $40 \%$ of cases $(10$, 56-60). Many of these caveats of the UBT and SAT tests can be evaded by the GastroPanel ${ }^{\circledR}$ test (26), which distinguishes 3 diagnostic profiles that specify i) an actively ongoing $\mathrm{Hp}-$ infection, b) successful Hp-eradication, and c) failed Hperadication $(23,26,29,30)$.

The Hp IgG ELISA component of the new-generation GP test was validated recently in a population with a high (64\% biopsy-confirmed) prevalence of Hp-infection (49). In this population, the overall agreement between $\mathrm{Hp} \mathrm{IgG} \mathrm{ELISA} \mathrm{and}$ gastric biopsies in $\mathrm{Hp}$-detection was $91 \%$, with $\mathrm{AUC}=0.978$ (49). In the present study of a population with biopsy-confirmed Hp-prevalence of 7.8\% (Table II and Table III), the diagnostic accuracy of the $\mathrm{Hp} \operatorname{IgG}$ ELISA is even more impressive: AUC $=0.993$ (Figure 3), OA 497/511 (97.2\%), SE of $95.0 \%$ $(95 \% \mathrm{CI}=83.1-99.4 \%)$ and $\mathrm{SP}$ of $97.5 \%(95 \% \mathrm{CI}=95.6-98.7 \%)$, using biopsy-confirmed $\mathrm{Hp}$ as the reference.

In 1975 , Fagan introduced a nomogram to quantify a posttest probability for individuals to be affected by a condition, based on the probability of the condition before the test (pretest probability) (52). When adopted to the present data ( $\mathrm{LR}+$, LR-), the Fagan's nomogram (Figure 4) implicates that a GP test result of AGC predicts the diagnosis of $\mathrm{AGC} 2+$ in a population, with the likelihood of $80 \%$, whereas such a likelihood is close to $0 \%(0.4 \%)$ if the GP test result is negative for AGC. Assuming that the study sample is representative of the entire population, an estimate of the pre-test probability reflects the global prevalence of this disorder (52).

\section{Conclusion}

The present clinical validation study confirms the diagnostic accuracy of the unified GastroPanel ${ }^{\circledR}$ test in gastroscopy referral patients, supporting our previous results in different settings (48, 49). GastroPanel ${ }^{\circledR}$ biomarkers PGI and PGI/PGII ratio as well as Hp IgG ELISA are equally accurate in diagnosing AGC and $\mathrm{Hp}$-infection in the biopsies, respectively. Diagnosis of AGA by G-17 is less accurate, however, due to the dual physiological role of G-17 as a biomarker of i) antrum atrophy and ii) high-acid output of the corpus, thus inflating its diagnostic accuracy for AGA. Being closely concordant with biopsy histology, the GastroPane ${ }^{\circledR}$ test offers a non-invasive alternative for invasive gastroscopy in the diagnosis of dyspeptic patients. When the AGprofile of the GP test is being used as the indication for gastroscopy, substantial cost savings are achieved by cancelling unnecessary gastroscopies particularly in populations with low to moderate prevalence of $\mathrm{AG}$ (and $\mathrm{Hp}$ ).

\section{Conflicts of Interest}

The Authors declare no conflicts of interest.

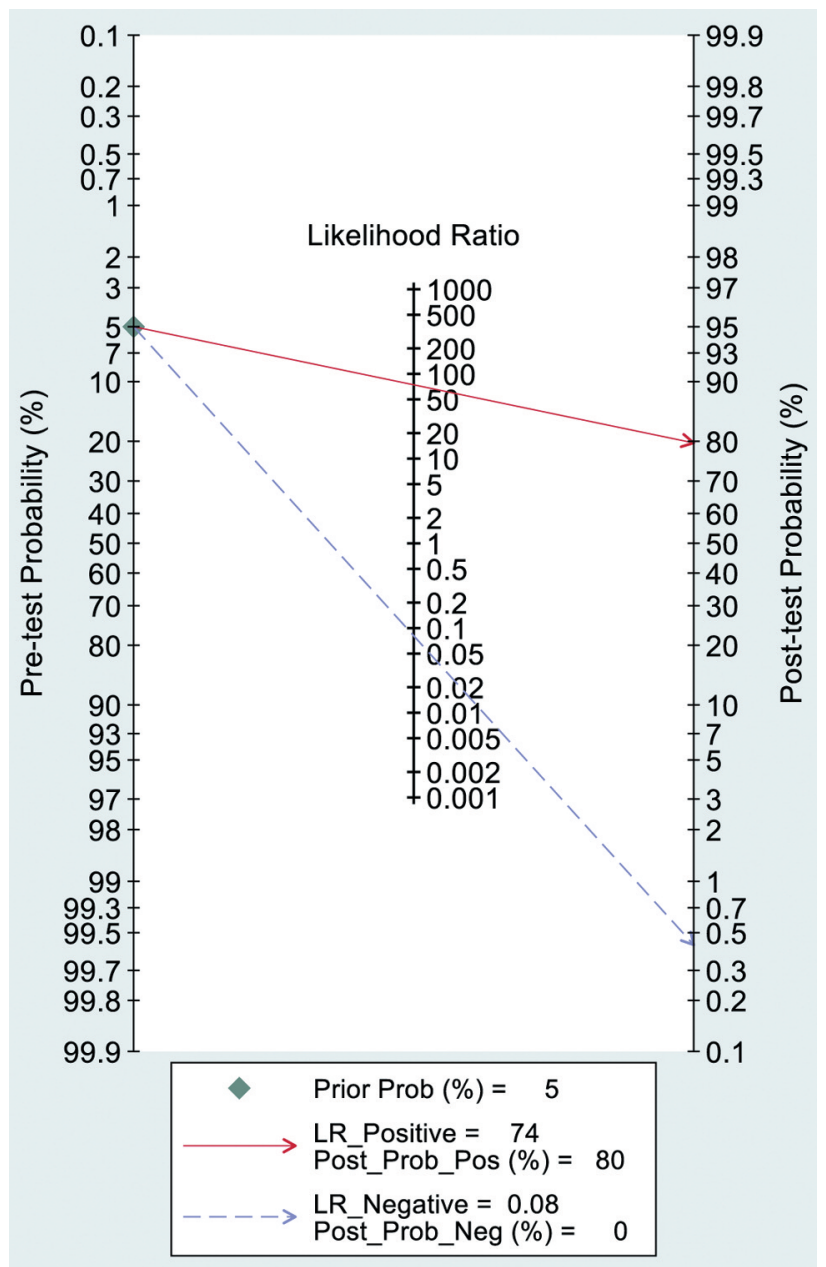

Figure 4. Fagan's nomogram for GastroPanel ${ }^{\circledR}$ as predictor of atrophic corpus gastritis (AGC) in a population with a comparable disease prevalence.

\section{Authors' Contributions}

All Authors have met all the following four criteria: i) Substantial contributions to the conception or design of the work or the acquisition, analysis, or interpretation of data for the work. ii) Drafting of the work or revising it critically for important intellectual content. iii) Final approval of the version to be published. iv) Agreement to be accountable for all aspects of the work in ensuring that questions related to the accuracy or integrity of any part of the work are appropriately investigated and resolved.

\section{Acknowledgements}

This study was funded by a non-restricted research grant from Biohit Oyj (Helsinki, Finland). The skilful technical assistance of the following persons are gratefully acknowledged for their important input in the different phases of the study: Mrs. Leena Ukkola, Mrs. Heidi Häikiö, Mrs. Saara Korhonen, Mrs. Saija 
Kortetjärvi, Mrs. Marita Koistinen, Mrs. Katja Eronen, Mrs. Anita Mikkola, Mrs. Kaisa Friberg, Ms. Milla Mikkola, Mrs. Pia Rinkinen, Dr. Tapani Tiusanen, PhD, Dr. Minna Mäki, PhD, Suvi Elomaa, B.Sc. and Mrs. Heli Holopainen.

\section{References}

1 Sung H, Ferlay J, Siegel RL, Laversanne M, Soerjomataram I, Jemal A and Bray F: Global cancer statistics 2020: GLOBOCAN estimates of incidence and mortality worldwide for 36 cancers in 185 countries. CA Cancer J Clin 71(3): 209-249, 2021. PMID: 33538338. DOI: $10.3322 /$ caac. 21660

2 Howson CP, Hiyama T and Wynder EL: The decline in gastric cancer: epidemiology of an unplanned triumph. Epidemiol Rev 8: 1-27, 1986. PMID: 3533579. DOI: 10.1093/oxfordjournals. epirev.a036288

3 Correa P, Haenszel W, Cuello C, Zavala D, Fontham E, Zarama G, Tannenbaum S, Collazos T and Ruiz B: Gastric precancerous process in a high risk population: cohort follow-up. Cancer Res 50(15): 4737-4740, 1990. PMID: 2369748.

4 Plummer M, Franceschi S and Muñoz N: Epidemiology of gastric cancer. IARC Sci Publ (157): 311-326, 2004. PMID: 15055304.

5 Buckland G, Agudo A, Luján L, Jakszyn P, Bueno-de-Mesquita HB, Palli D, Boeing H, Carneiro F, Krogh V, Sacerdote C, Tumino R, Panico S, Nesi G, Manjer J, Regnér S, Johansson I, Stenling R, Sanchez MJ, Dorronsoro M, Barricarte A, Navarro C, Quirós JR, Allen NE, Key TJ, Bingham S, Kaaks R, Overvad $\mathrm{K}$, Jensen M, Olsen A, Tjønneland A, Peeters PH, Numans ME, Ocké MC, Clavel-Chapelon F, Morois S, Boutron-Ruault MC, Trichopoulou A, Lagiou P, Trichopoulos D, Lund E, Couto E, Boffeta P, Jenab M, Riboli E, Romaguera D, Mouw $\mathrm{T}$ and González CA: Adherence to a Mediterranean diet and risk of gastric adenocarcinoma within the European Prospective Investigation into Cancer and Nutrition (EPIC) cohort study. Am J Clin Nutr 91(2): 381-390, 2010. PMID: 20007304. DOI: 10.3945/ajen.2009.28209

6 Marshall BJ and Warren JR: Unidentified curved bacilli in the stomach of patients with gastritis and peptic ulceration. Lancet 1(8390): 1311-1315, 1984. PMID: 6145023. DOI: 10.1016/ s0140-6736(84)91816-6

7 Sipponen P and Marshall BJ: Gastritis and gastric cancer. Western countries. Gastroenterol Clin North Am 29(3): 579-92, v-vi, 2000. PMID: 11030074. DOI: 10.1016/s0889-8553(05)70131-x

8 International Agency for Research on Cancer, World Health Organization: Schistosomes, liver flukes and Helicobacter pylori. IARC working group on the evaluation of carcinogenic risks to human. No. 61. Monogr Eval Carcinog Risks Hum 61: 218-220, 1994.

9 Malfertheiner P, Sipponen P, Naumann M, Moayyedi P, Mégraud F, Xiao SD, Sugano K, Nyrén O and Lejondal H. pylori-Gastric Cancer Task Force: Helicobacter pylori eradication has the potential to prevent gastric cancer: a state-of-the-art critique. Am J Gastroenterol 100(9): 2100-2115, 2005. PMID: 16128957. DOI: $10.1111 / \mathrm{j} .1572-0241.2005 .41688 . \mathrm{x}$

10 Malfertheiner P, Megraud F, O'Morain CA, Gisbert JP, Kuipers EJ, Axon AT, Bazzoli F, Gasbarrini A, Atherton J, Graham DY, Hunt R, Moayyedi P, Rokkas T, Rugge M, Selgrad M, Suerbaum S, Sugano K, El-Omar EM and European Helicobacter and Microbiota Study Group and Consensus panel: Management of
Helicobacter pylori infection-the Maastricht V/Florence Consensus Report. Gut 66(1): 6-30, 2017. PMID: 27707777. DOI: $10.1136 /$ gutjnl-2016-312288

11 Uemura N, Okamoto S, Yamamoto S, Matsumura N, Yamaguchi S, Yamakido M, Taniyama K, Sasaki N and Schlemper RJ: Helicobacter pylori infection and the development of gastric cancer. N Engl J Med 345(11): 784-789, 2001. PMID: 11556297. DOI: 10.1056/NEJMoa001999

12 Ohata H, Kitauchi S, Yoshimura N, Mugitani K, Iwane M, Nakamura H, Yoshikawa A, Yanaoka K, Arii K, Tamai H, Shimizu Y, Takeshita T, Mohara O and Ichinose M: Progression of chronic atrophic gastritis associated with Helicobacter pylori infection increases risk of gastric cancer. Int J Cancer 109(1): 138-143, 2004. PMID: 14735480. DOI: 10.1002/ijc. 11680

13 Varis K, Sipponen P, Laxén F, Samloff IM, Huttunen JK, Taylor PR, Heinonen OP, Albanes D, Sande N, Virtamo J and Härkönen M: Implications of serum pepsinogen I in early endoscopic diagnosis of gastric cancer and dysplasia. Helsinki Gastritis Study Group. Scand J Gastroenterol 35(9): 950-956, 2000. PMID: 11063155. DOI: 10.1080/003655200750023011

14 Dixon MF, Genta RM, Yardley JH and Correa P: Classification and grading of gastritis. The updated Sydney System. International Workshop on the Histopathology of Gastritis, Houston 1994. Am J Surg Pathol 20(10): 1161-1181, 1996. PMID: 8827022. DOI: 10.1097/00000478-199610000-00001

15 Moayyedi P, Talley NJ, Fennerty MB and Vakil N: Can the clinical history distinguish between organic and functional dyspepsia? JAMA 295(13): 1566-1576, 2006. PMID: 16595759. DOI: $10.1001 /$ jama.295.13.1566

16 Weck MN, Stegmaier C, Rothenbacher D and Brenner H: Epidemiology of chronic atrophic gastritis: population-based study among 9444 older adults from Germany. Aliment Pharmacol Ther 26(6): 879-887, 2007. PMID: 17767472. DOI: 10.1111/j.1365-2036.2007.03430.x

17 Sipponen P and Price AB: The Sydney System for classification of gastritis 20 years ago. J Gastroenterol Hepatol 26(Suppl 1): 31-34, 2011. PMID: 21199511. DOI: 10.1111/j.1440-1746.2010. 06536.x

18 Lomba-Viana R, Dinis-Ribeiro M, Fonseca F, Vieira AS, Bento MJ and Lomba-Viana H: Serum pepsinogen test for early detection of gastric cancer in a European country. Eur J Gastroenterol Hepatol 24(1): 37-41, 2012. PMID: 21989121. DOI: 10.1097/MEG.0b013e32834d0a0a

19 Bornschein J, Selgrad M, Wex T, Kuester D and Malfertheiner P: Serological assessment of gastric mucosal atrophy in gastric cancer. BMC Gastroenterol 12: 10, 2012. PMID: 22289789. DOI: $10.1186 / 1471-230 X-12-10$

20 Germaná B, Di Mario F, Cavallaro LG, Moussa AM, Lecis P, Liatoupolou S, Comparato G, Carloni C, Bertiato G, Battiestel M, Papa N, Aragona G, Cavestro GM, Iori V, Merli R, Bertolini S, Caruana $\mathrm{P}$ and Franzé A: Clinical usefulness of serum pepsinogens I and II, gastrin-17 and anti-Helicobacterpylori antibodies in the management of dyspeptic patients in primary care. Dig Liver Dis 37(7): 501-508, 2005. PMID: 15975537. DOI: $10.1016 /$ j.dld.2005.01.016

21 Miki K, Ichinose M, Shimizu A, Huang SC, Oka H, Furihata C, Matsushima T and Takahashi K: Serum pepsinogens as a screening test of extensive chronic gastritis. Gastroenterol Jpn 22(2): 133141, 1987. PMID: 3596151. DOI: 10.1007/BF02774209 
22 Samloff IM, Varis K, Ihamaki T, Siurala M and Rotter JI: Relationships among serum pepsinogen I, serum pepsinogen II, and gastric mucosal histology. A study in relatives of patients with pernicious anemia. Gastroenterology 83(1 Pt 2): 204-209, 1982. PMID: 7084603.

23 Biohit HealthCare. GastroPanel. Available at: https://www. gastropanel.com/healthcare-professionals-and-laboratories/formsand-instructions [Last accessed on August 17, 2021]

24 Korstanje A, den Hartog G, Biemond I and Lamers CB: The serological gastric biopsy: a non-endoscopical diagnostic approach in management of the dyspeptic patient: significance for primary care based on a survey of the literature. Scand J Gastroenterol Suppl (236): 22-26, 2002. PMID: 12408500. DOI: $10.1080 / 003655202320621418$

25 Oksanen A, Sipponen P, Miettinen A, Sarna S and Rautelin H: Evaluation of blood tests to predict normal gastric mucosa. Scand J Gastroenterol 35(8): 791-795, 2000. PMID: 10994615. DOI: $10.1080 / 003655200750023138$

26 Syrjänen K: Serological biomarker panel (GastroPanel ${ }^{\circledR}$ ): A test for non-invasive diagnosis of dyspeptic symptoms and for comprehensive detection of Helicobacter pylori infection. Biomark J 3: 1-10, 2017. DOI: 10.21767/2472-1646.100024

27 Miki K: Gastric cancer screening using the serum pepsinogen test method. Gastric Cancer 9(4): 245-253, 2006. PMID: 17235625. DOI: $10.1007 / \mathrm{s} 10120-006-0397-0$

28 Agréus L, Kuipers EJ, Kupcinskas L, Malfertheiner P, Di Mario F, Leja M, Mahachai V, Yaron N, van Oijen M, Perez Perez G, Rugge M, Ronkainen J, Salaspuro M, Sipponen P, Sugano K and Sung J: Rationale in diagnosis and screening of atrophic gastritis with stomach-specific plasma biomarkers. Scand J Gastroenterol 47(2): 136-147, 2012. PMID: 22242613. DOI: 10.3109/003 65521.2011 .645501

29 GastroPanel. Available at: https://www.gastropanel.com/ [Last accessed on 20 August 2021]

30 Syrjänen K, Eskelinen M, Peetsalu A, Sillakivi T, Sipponen P, Härkönen M, Paloheimo L, Mäki M, Tiusanen T, Suovaniemi O, DiMario F and Fan ZP: GastroPane ${ }^{\circledR}$ Biomarker Assay: The most comprehensive test for Helicobacter pylori infection and its clinical sequelae. A critical review. Anticancer Res 39(3): 10911104, 2019. PMID: 30842138. DOI: 10.21873/anticanres.13218

31 Syrjänen K: A panel of serum biomarkers (GastroPanel ${ }^{\circledR}$ ) in non-invasive diagnosis of atrophic gastritis. Systematic review and meta-analysis. Anticancer Res 36(10): 5133-5144, 2016. PMID: 27798873. DOI: 10.21873/anticanres.11083

32 Iijima K, Abe Y, Kikuchi R, Koike T, Ohara S, Sipponen P and Shimosegawa T: Serum biomarker tests are useful in delineating between patients with gastric atrophy and normal, healthy stomach. World J Gastroenterol 15(7): 853-859, 2009. PMID: 19230047. DOI: 10.3748/wjg.15.853

33 Di Mario F, Moussa AM, Caruana P, Merli R, Cavallaro LG, Cavestro GM, Dal Bò N, Iori V, Pilotto A, Leandro G, Franzè A and Rugge M: 'Serological biopsy' in first-degree relatives of patients with gastric cancer affected by Helicobacter pylori infection. Scand J Gastroenterol 38(12): 1223-1227, 2003. PMID: 14750641. DOI: 10.1080/00365520310007044

34 Väänänen H, Vauhkonen M, Helske T, Kääriäinen I, Rasmussen M, Tunturi-Hihnala H, Koskenpato J, Sotka M, Turunen M, Sandström R, Ristikankare M, Jussila A and Sipponen P: Nonendoscopic diagnosis of atrophic gastritis with a blood test. Correlation between gastric histology and serum levels of gastrin-17 and pepsinogen I: a multicentre study. Eur J Gastroenterol Hepatol 15(8): 885-891, 2003. PMID: 12867799. DOI: $10.1097 / 00042737-200308000-00009$

35 Hartleb M, Wandzel P, Waluga M, Matyszczyk B, Bołdys H and Romañczyk T: Non-endoscopic diagnosis of multifocal atrophic gastritis; efficacy of serum gastrin-17, pepsinogens and Helicobacter pylori antibodies. Acta Gastroenterol Belg 67(4): 320-326, 2004. PMID: 15727075.

36 Pasechnikov VD, Chukov SZ, Kotelevets SM, Mostovov AN, Mernova VP and Polyakova MB: Possibility of non-invasive diagnosis of gastric mucosal precancerous changes. World $\mathrm{J}$ Gastroenterol 10(21): 3146-3150, 2004. PMID: 15457561. DOI: 10.3748/wjg.v10.i21.3146

37 Pasechnikov VD, Chukov SZ, Kotelevets SM, Mostovov AN, Mernova VP and Polyakova MB: Invasive and non-invasive diagnosis of Helicobacter pylori-associated atrophic gastritis: a comparative study. Scand J Gastroenterol 40(3): 297-301, 2005. PMID: 15932170. DOI: 10.1080/00365520410010607

38 Nardone G, Rocco A, Staibano S, Mezza E, Autiero G, Compare D, De Rosa G and Budillon G: Diagnostic accuracy of the serum profile of gastric mucosa in relation to histological and morphometric diagnosis of atrophy. Aliment Pharmacol Ther 22(1112): 1139-1146, 2005. PMID: 16305728. DOI: 10.1111/j.13652036.2005.02734.x

39 Graham DY, Nurgalieva ZZ, El-Zimaity HM, Opekun AR, Campos A, Guerrero L, Chavez A and Cardenas V: Noninvasive versus histologic detection of gastric atrophy in a Hispanic population in North America. Clin Gastroenterol Hepatol 4(3): 306-314, 2006. PMID: 16527693. DOI: 10.1016/j.cgh.2005.11.003

40 Storskrubb T, Aro P, Ronkainen J, Sipponen P, Nyhlin H, Talley NJ, Engstrand L, Stolte M, Vieth M, Walker M and Agréus L: Serum biomarkers provide an accurate method for diagnosis of atrophic gastritis in a general population: The Kalixanda study. Scand J Gastroenterol 43(12): 1448-1455, 2008. PMID: 18663663. DOI: 10.1080/00365520802273025

41 Zagari RM, Rabitti S, Greenwood DC, Eusebi LH, Vestito A and Bazzoli F: Systematic review with meta-analysis: diagnostic performance of the combination of pepsinogen, gastrin-17 and anti-Helicobacter pylori antibodies serum assays for the diagnosis of atrophic gastritis. Aliment Pharmacol Ther 46(7): 657-667, 2017. PMID: 28782119. DOI: 10.1111/apt.14248

42 Bang CS, Lee JJ and Baik GH: Prediction of chronic atrophic gastritis and gastric neoplasms by serum pepsinogen assay: a systematic review and meta-analysis of diagnostic test accuracy. J Clin Med 8(5): 657, 2019. PMID: 31083485. DOI: 10.3390/ jcm8050657

43 Coelho MCF, Ribeiro HG, Gomes CGO, Marinho FP, Barbosa AJA and Coelho LGV: Helicobacter pylori chronic gastritis on patients with premalignant conditions: OLGA and OLGIM evaluation and serum biomarkers performance. Arq Gastroenterol 58(1): 39-47, 2021. PMID: 33909795. DOI: 10.1590/S0004-2803.202100000-08

44 Mattar R, Marques SB, Ribeiro IB, Visconti TAC, Funari M and DE Moura EGH: Diagnostic accuracy of GastroPanel ${ }^{\circledR}$ for atrophic gastritis in Brazilian subjects and the effect of proton pump inhibitors. Arq Gastroenterol 57(2): 154-160, 2020. PMID: 32609157. DOI: 10.1590/S0004-2803.202000000-29

45 Yuan L, Zhao JB, Zhou YL, Qi YB, Guo QY, Zhang HH, Khan MN, Lan L, Jia CH, Zhang YR and Ding SZ: Type I and type II Helicobacter pylori infection status and their impact on gastrin 
and pepsinogen level in a gastric cancer prevalent area. World $\mathrm{J}$ Gastroenterol 26(25): 3673-3685, 2020. PMID: 32742135. DOI: 10.3748/wjg.v26.i25.3673

46 Mansour-Ghanaei F, Joukar F, Baghaee M, Sepehrimanesh M and Hojati A: Only serum pepsinogen I and pepsinogen I/II ratio are specific and sensitive biomarkers for screening of gastric cancer. Biomol Concepts 10(1): 82-90, 2019. PMID: 31188744 DOI: $10.1515 / \mathrm{bmc}-2019-0010$

47 Yu G, Wang GX, Wang HG, Mo FF and Tang BB: The value of detecting pepsinogen and gastrin-17 levels in serum for precancerous lesion screening in gastric cancer. Neoplasma 66(4): 637640, 2019. PMID: 31058531. DOI: 10.4149/neo_2018_18082 5 N647

48 Koivurova, O-P, Ukkola O, Koivikko M, Ebeling T, Yliaska I, Koskela R, Blomster T, Ala-Rämi A, Kettunen O, Karttunen T.J. Mäkinen M, Ronkainen J and Syrjänen K: Screening of the patients with autoimmune thyroid disease (AITD) and type 1 diabetes mellitus (DM1) for atrophic gastritis (AG) by serological biomarker testing (GastroPanel ${ }^{\circledR}$ ). EC Gastroenterol Digest Syst 7(8): 181-195, 2020.

49 Mäki M, Söderström D, Paloheimo L, Hendolin P, Suovaniemi $\mathrm{O}$ and Syrjänen K: Helicobacter pylori $(\mathrm{Hp}) \mathrm{IgG}$ ELISA of the new-generation GastroPanel ${ }^{\circledR}$ is highly accurate in diagnosis of $\mathrm{Hp}$-infection in gastroscopy referral patients. Anticancer Res 40(11): 6387-6398, 2020. PMID: 33109577. DOI: 10.21873/ anticanres. 14660

50 Aro P, Ronkainen J, Storskrubb T, Bolling-Sternevald E, Svärdsudd K, Talley NJ, Junghard O, Johansson SE, Wiklund I and Agréus L: Validation of the translation and cross-cultural adaptation into Finnish of the Abdominal Symptom Questionnaire, the Hospital Anxiety and Depression Scale and the Complaint Score Questionnaire. Scand J Gastroenterol 39(12): 1201-1208, 2004. PMID: 15742996 . DOI: 10.1080/00365520410008132

51 Seed PT and Tobias A: Summary statistics for diagnostic tests. Stata Techn Bull 59(1): 9-12, 2001.

52 Fagan TJ: Letter: Nomogram for Bayes theorem. N Engl J Med 293(5): 257, 1975. PMID: 1143310. DOI: 10.1056/NEJM19 7507312930513

53 Syrjänen KJ, Sipponen P, Härkönen M, Peetsalu A and Korpela S: Accuracy of the GastroPanel test in the detection of atrophic gastritis. Eur J Gastroenterol Hepatol 27(1): 102-104, 2015. PMID: 25426982. DOI: 10.1097/MEG.0000000000000215

54 Telaranta-Keerie A, Kara R, Paloheimo L, Härkönen M and Sipponen P: Prevalence of undiagnosed advanced atrophic corpus gastritis in Finland: an observational study among 4,256 volunteers without specific complaints. Scand J Gastroenterol 45(9): 10361041, 2010. PMID: 20446846. DOI: 10.3109/00365521.2010. 487918
55 Rugge M, Genta RM, Fassan M, Valentini E, Coati I, Guzzinati S, Savarino E, Zorzi M, Farinati F and Malfertheiner P: OLGA gastritis staging for the prediction of gastric cancer risk: a longterm follow-up study of 7436 patients. Am J Gastroenterol 113(11): 1621-1628, 2018. PMID: 30333540. DOI: 10.1038/s41395-018-0353-8

56 Fritz N, Birkner B, Schusdziarra V, Borlinghaus KP, Burlefinger R, Dettmer A, Heldwein W, Henke M, Höchter W, Janetschek P, Kunze R, Schatke W, Strauch M, Struppler C, Weingart J and Rösch T: Are guidelines followed in Helicobacter pylori diagnosis and therapy? An inquiry among gastroenterologists, referring physicians and patients in Munich. Z Gastroenterol 38(5): 349-355, 2000. PMID: 10875143. DOI: 10.1055/s-200014876

57 Zagari RM, Romano M, Ojetti V, Stockbrugger R, Gullini S, Annibale B, Farinati F, Ierardi E, Maconi G, Rugge M, Calabrese C, Di Mario F, Luzza F, Pretolani S, Savio A, Gasbarrini G and Caselli M: Guidelines for the management of Helicobacter pylori infection in Italy: The III Working Group Consensus Report 2015. Dig Liver Dis 47(11): 903-912, 2015. PMID: 26253555. DOI: 10.1016/j.dld.2015.06.010

58 Malfertheiner P, Mégraud F, O’Morain C, Hungin AP, Jones R, Axon A, Graham DY, Tytgat G and European Helicobacter Pylori Study Group (EHPSG): Current concepts in the management of Helicobacter pylori infection - the Maastricht 2-2000 Consensus Report. Aliment Pharmacol Ther 16(2): 167-180, 2002. PMID: 11860399. DOI: 10.1046/j.1365-2036.2002.01169.x

59 Malfertheiner P, Megraud F, O’Morain C, Bazzoli F, El-Omar E, Graham D, Hunt R, Rokkas T, Vakil N and Kuipers EJ: Current concepts in the management of Helicobacter pylori infection: the Maastricht III Consensus Report. Gut 56(6): 772-781, 2007. PMID: 17170018. DOI: 10.1136/gut.2006.101634

60 Marshall B: The 14C urea breath test. In: Lee A, Megraud F. (eds). Helicobacter pylori: Techniques for Clinical Diagnosis and Basic Research. 2nd Ed. London, WB Saunders Company, pp. 83-93, 1996.
Received September 4, 2021

Revised October 7, 2021

Accepted October 21, 2021 